\title{
OFFICE BUILDINGS DESIGN AND ITS IMPACT ON ENERGY SAVING (RECENT TECHNOLOGY SYSTEMS AND MATERIALS)
}

\author{
Emad Fahim matta ${ }^{1}$ and Sally Hosny Alkholy ${ }^{2}$ \\ ${ }^{1}$ Architecture in Helwan University - Mataria branch \\ ${ }^{2}$ Architecture Engineer in New Cairo Authority
}

\begin{abstract}
Decreasing Energy wasting in Egypt was and still very essential, especially in the office buildings that needs huge expenses during operation process due to the increase of energy consumption. To achieve the least average of energy consumption in office buildings it was necessary to make good use of recent modern technology in architecture, accordingly the study is divided into two parts which are the theoretical study and the analytical study. Theoretical study brings to light the up to date methods and different styles to depend on in order to save energy in types of modern architecture either in the design in general or in the facades of these buildings in particular. The analytical study is concerned with studying global examples that care about using modern materials and systems that save energy and also measure the rate of using those different materials and systems in order to figure out the best of those modern materials and systems that the architect can depend on during the design of office buildings facades.
\end{abstract}

Key Words: Office Buildings - Elevations Design - Recent Building Materials Recent Building Systems - Energy Saving.

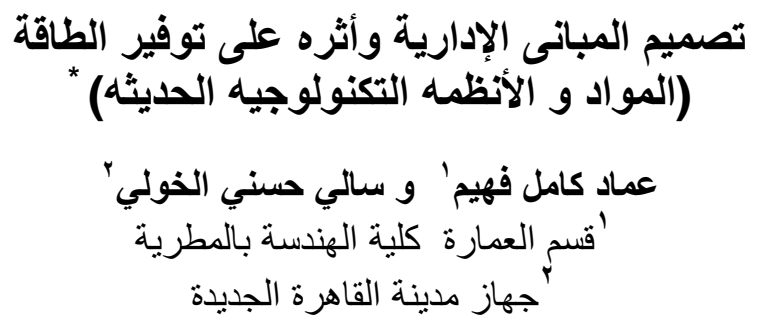

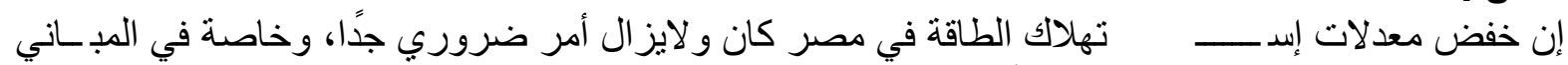

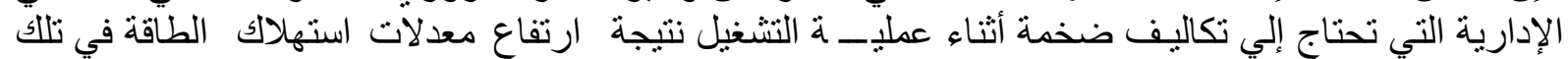

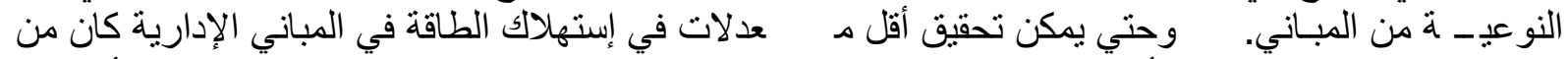

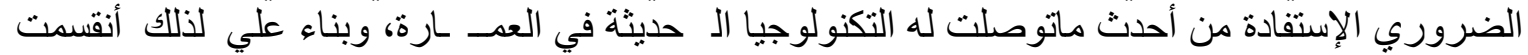

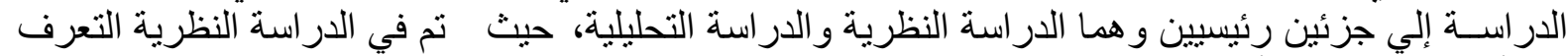

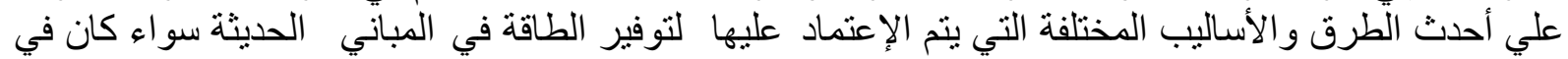

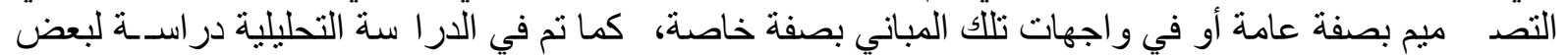

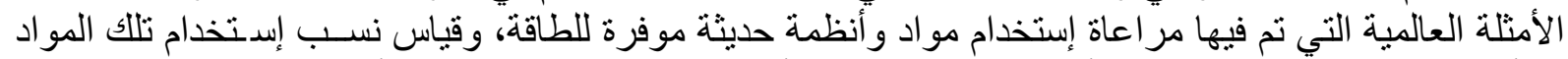

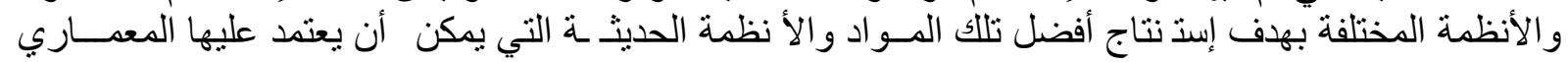
في تصميم و اجهات المباني الإداريـة. 


\title{
الكلمات الدالة : المباني الإدارية، تصميم الواجهات مواد البناء الحديثه، ال لأنظمه التكنولوجيه
} الحديثه، توفير الطاقه.

\author{
مق بحث للنشر من منطلبات الحصول علي الدكتور اه " تصميم المباني الإدارية واثره علي توفير الطاقة"
}

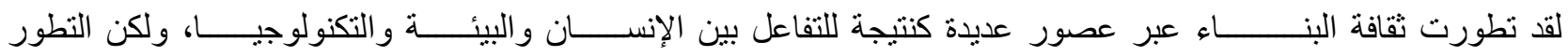

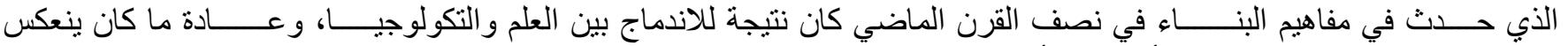

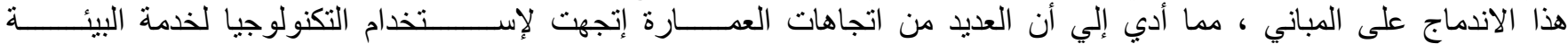

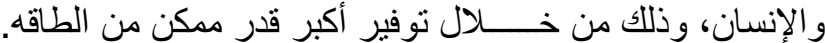

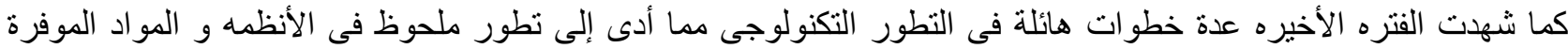

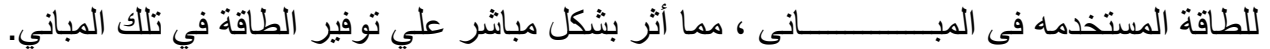

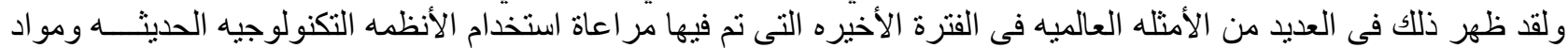

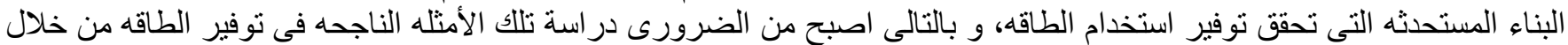

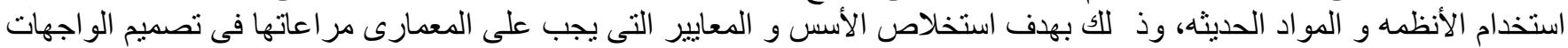

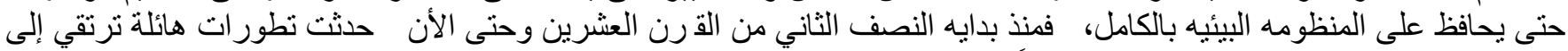

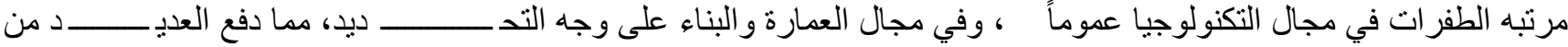

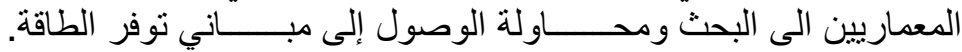
مشكلة البحث البث المثان

تتلخص المشكلة البحثية في أن معدلات إستهلاك الطاقة في المباني الإدارية في مصر ضخمة جداً وتعتبر بمثابة عائق ضخم

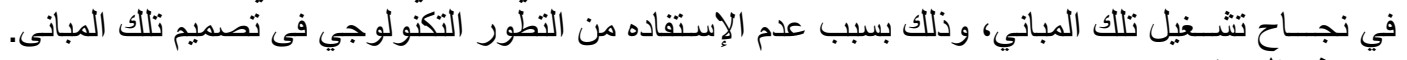

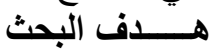
الهدف الرئيسي للبحث هو التعرف علي أهم مواد البناء الحديثة والأنظمة التكنولوجية الحديثة التي يمكن أن يستخدمها المعماري

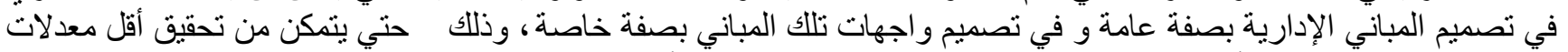

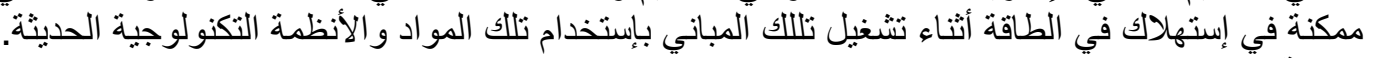
منهجية البحث البند تتقسم الدر اسة الى جز أين رئيسيين ، وهما الدر اسة النظرية و الدر اسة التحليلية.

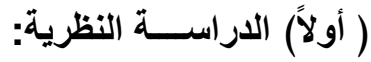

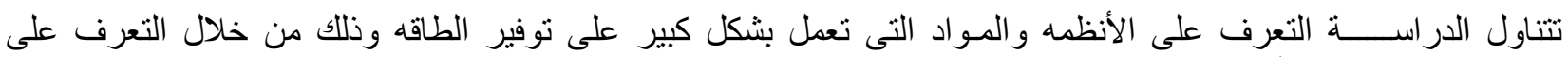
عمارة التكنولوجيا المتقدمه و الأنظمه و المواد الموفي الموفرة للطاقة.

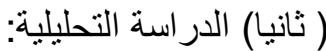

تهدف الدراسة الىى تأثثر النطور التكنولوجى على تصميم المبانى ودورها فى تحقيق كفاءة استخدام الطاقة، كما تشمل

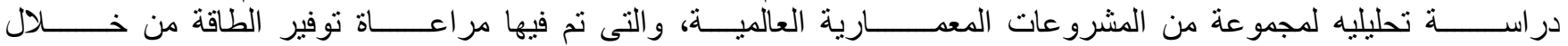

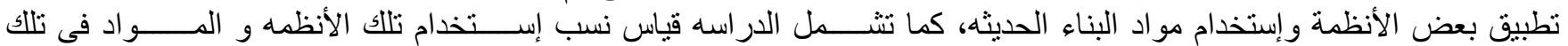

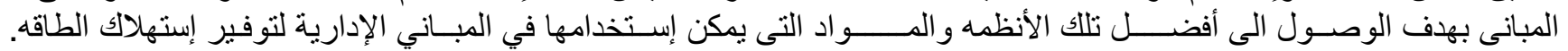

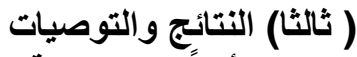

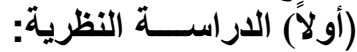
الأنظمة والتقنيات المتطورة الموفرة للطاقه:

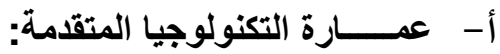

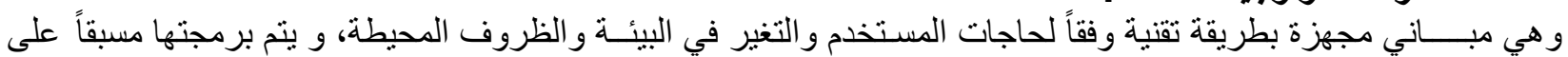

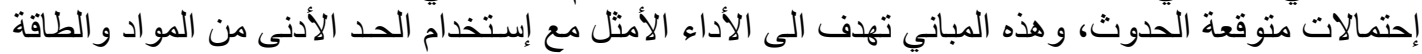
خصائص عمارة التكنولوجيا المتقدمة:

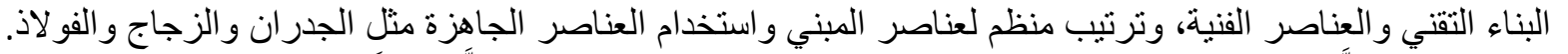

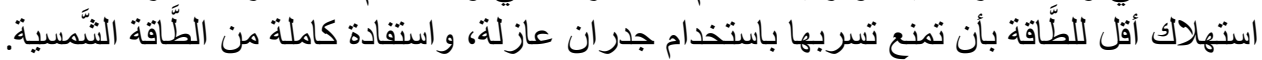

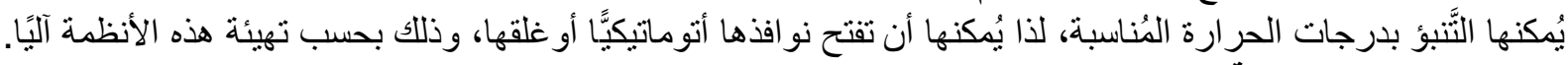

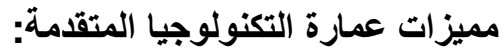

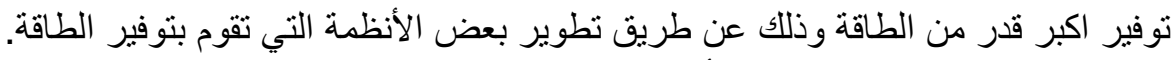

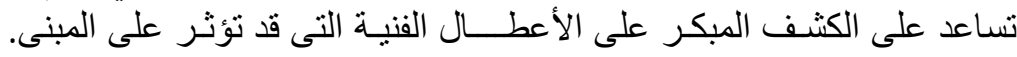
توفير راحة أكبر لمستخدمى المبنى. 


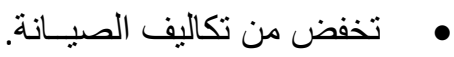

$$
\begin{aligned}
& \text { • • •وجه لاستيعاب و ادر اكل الأشكال الجمالية نتيجة التر اكيب المعدنية ( الحديدية ) مع الالواح الزجاجية. }
\end{aligned}
$$

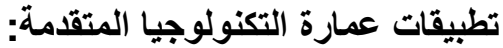

يمكن تطبيق عمارة التكنولوجيا المتقدمة في المباني من خلال (مو اد البناء الحديثه ، وتطبيق أنظمة التكنولوجيا الحديثه).

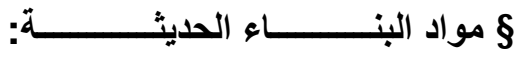
• ز زجاج النوافذ الموفرة للطاقه:

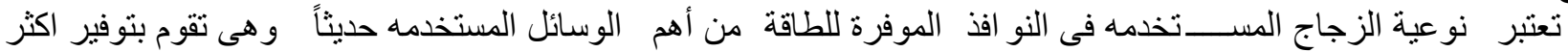

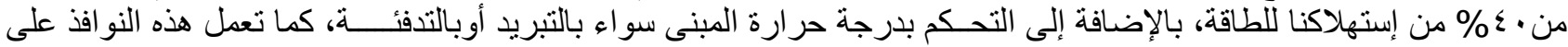
إدخال الإضاءه الطبيعيه للمبنى. :

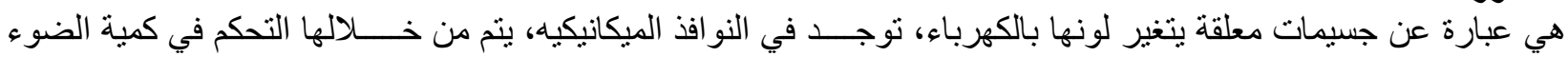

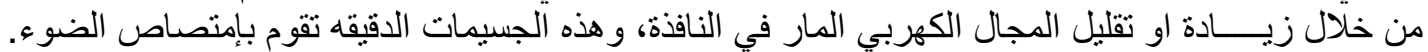

ß الأنظمة التكنولوجيا الحديثة:

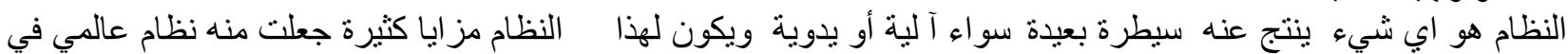

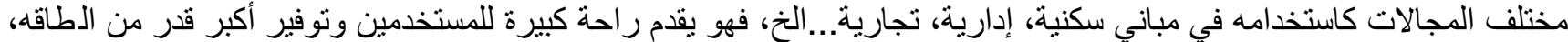

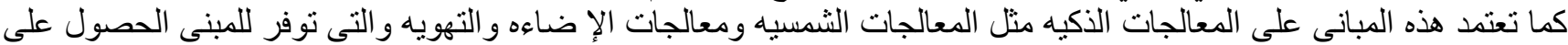

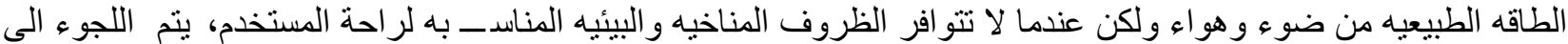

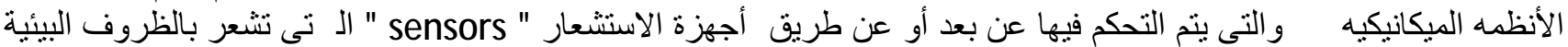

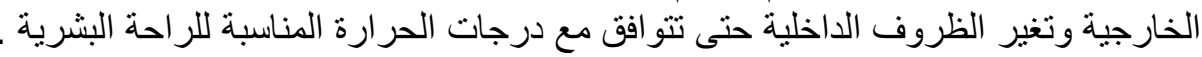

ومن أهم تلك الأنظمة المستخدمة:

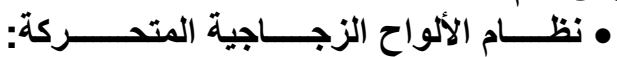

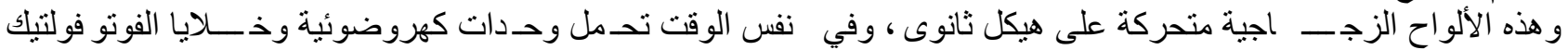

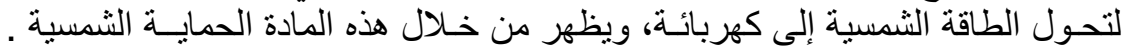

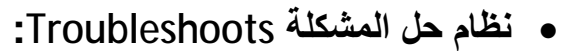

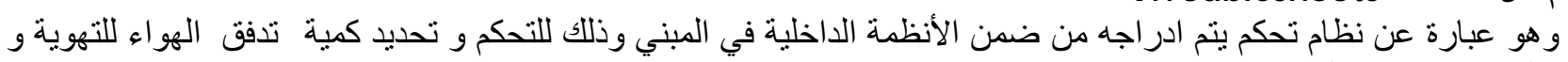
الحرارة و نسبة التبريد.

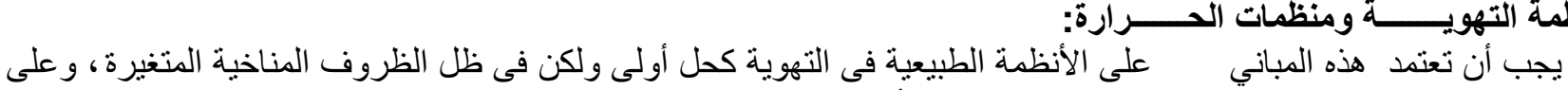

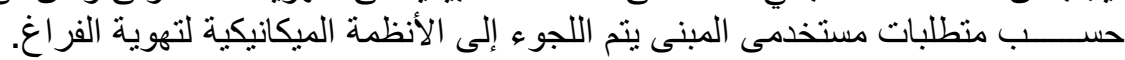

:BREATHING WINDOW نظام

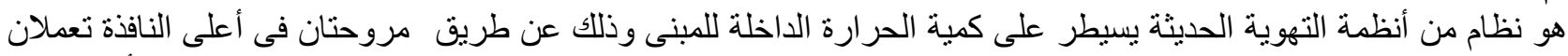

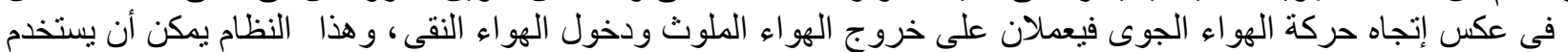

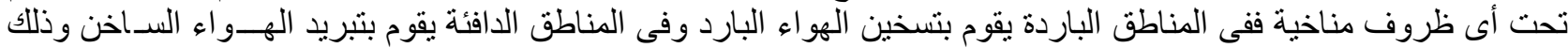

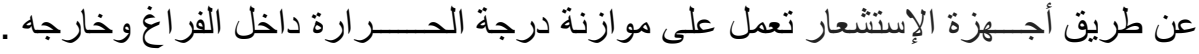

• نظام العواكس والعوارض الميكانيكية:

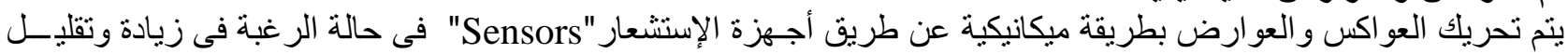

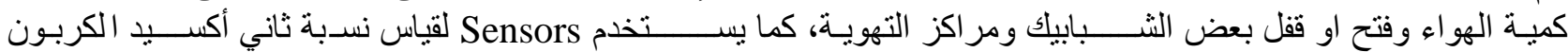

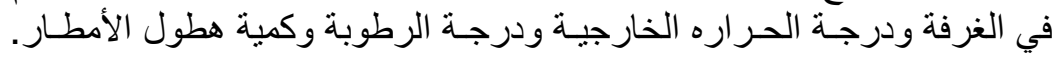

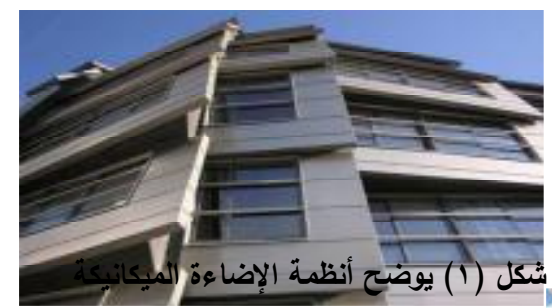

يعتبر نظام الإضاءة من أبرز الأنظمة فى هذه المبانى ووجود الإضـاءة

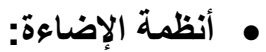

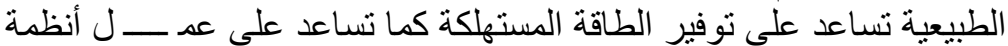

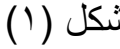

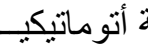

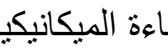 الإضــا 
يتم إستخدام نظام اللوحات الضوئية على الواجهات الخارجية بحيث أن هذه الألو اح تمتص أشعة الثمس المفيدة وتعكس الضــــار منها.

شكل (r) يوض:

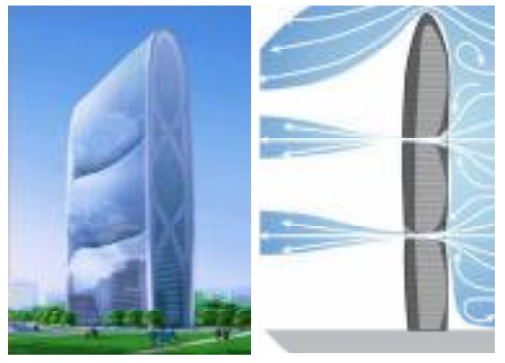

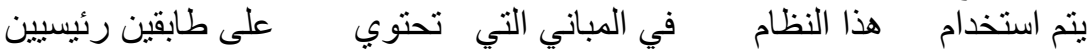

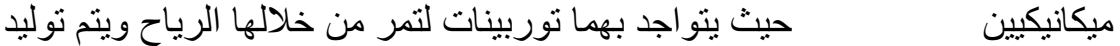

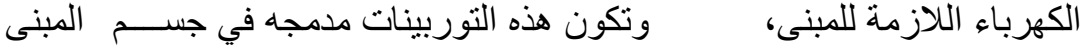

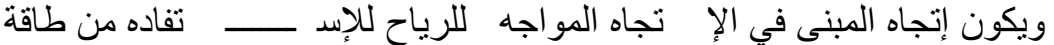

شكل (r) توضح حركة الرياح داخل المبني

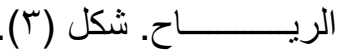

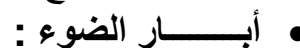

تفعيل ضوء النهار عن طريق إستخدام أبار الضوء التي تقوم بإلتقاط ضوء الثَدس و عكسه إلى داخل المبنى، وتوفر على ت كي كم في في

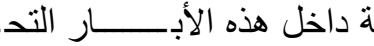

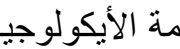

• مقارنة بين أنظمة عمارة التكونولجيا المتقدمة :

جدول ( ) مقارنه بين انظمة عمارة التكنولوجيا المتقدمة

\begin{tabular}{|c|c|c|c|}
\hline الأستخدام & 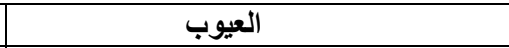 & 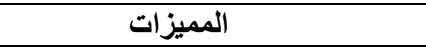 & 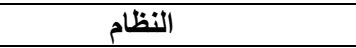 \\
\hline الأستخدام بشكل محدود & 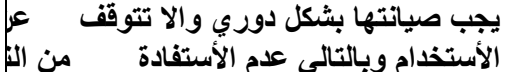 & 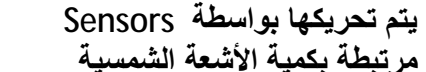 & 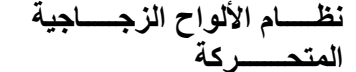 \\
\hline والأستخلام في المباني الأكية فق & الصيانة الدورية للنظام & في الفراغٌ المعمارية التهوية والحرارة & نظام حل المشكلة \\
\hline شائعة الأستخدام & تسريب لبعض الأتربة والهواء الضار للفر & التهوية الطبيعية في الفراغ المعماري & أنظمة التهويــــــــة ومنظمات \\
\hline محدود الأستخدام & تهالكه بة بثكل سريعة للنظام مما يؤدي & 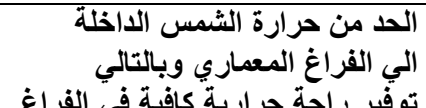 & SEATHING WINDOW نظام \\
\hline شائعة الأستخذام & 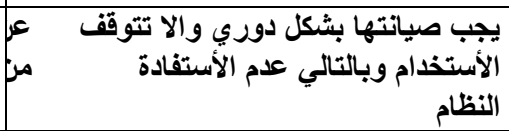 & 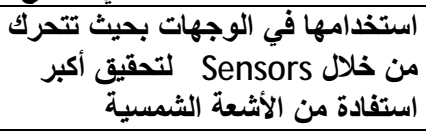 & نظام العواكس والعوارض \\
\hline شائعة الأستخدام & تشيداب للحرارة الشمس ان لم لم يتم معالج & الأضاءة الطبيعية في الفراغ المعماري & أنظمة الإضاءة \\
\hline شائعة الأستخدام & تسرب لتحرارة الشمس ان لم لم يتم معالج & الأستفادة من الأشعة الشمسية الطبية للحد من الأضاعة & نظام اللوحات الضوئية \\
\hline شائعة الأستخذام & تكلفة عالية & توفير الطاقة من خلال الرياح & توربينات الرياح \\
\hline محدود الأستخدام & لايوجد & تواخليز الضنوء من خلال ابار مدمجة & أبــــــــار الضوء \\
\hline
\end{tabular}

ب- - العمارة المتحركة:

و هي العمارة المسنتدة علي ديناميكة الحركة، حيث تعني ا لتغبير في الوقت ودخول البعد الر ابع الزمن في عملية التصميم لتصبح

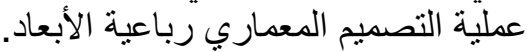
مميزات العمارة المتحركة:

تعطي العمارة المتحركه مرونة في الفراغ للتكيف مع إحتياجات الإنسان المختلفه، حيث يمكن توجيه الفر اغات المختلفة

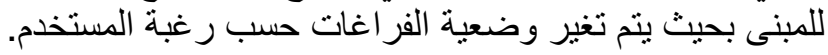

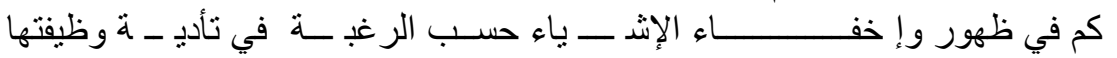
تعطي الإمكانية في التد

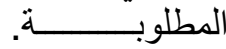
لها القدرة على إستيعاب الزيادة العددية وتلبية الإحتياجات المستقبلية للمباني، وذلك عن طريق التوسع في المساحات من خلال أنظمة التحكم. لها القدرة على تغير شكل الواجهات عن طريث إضافة وحذف أجز اء من الو اجهة للتكيف مع الوظيفة المطلوبة، وذللك من

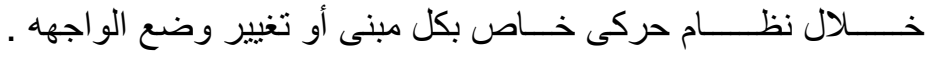




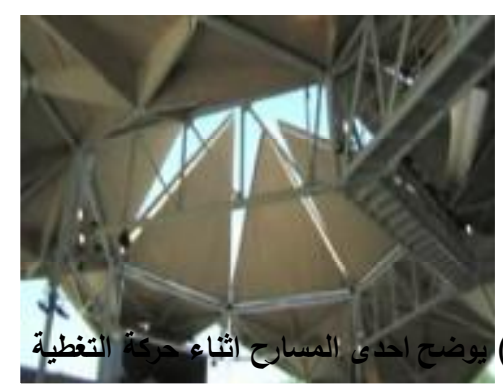

شكل (؛)

(و أجهزة
• أنظمة مدخلة أو متعددة المدخلات وأجهزة مر اقبتها :

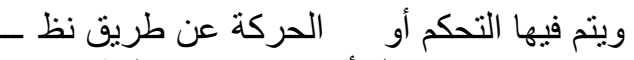

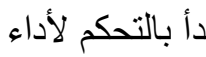

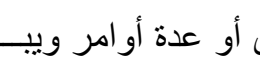

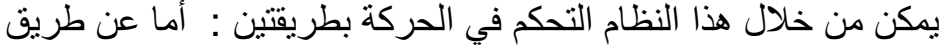

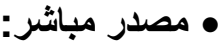

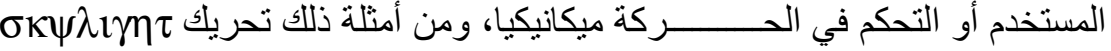

يتم التحكم فيه عن طريق إختيار ومعرفة أفضل الحلول التى تتاسب الوظيفة عن طريق الخبرات المتع ددة وكل هذا ينم بطريقة

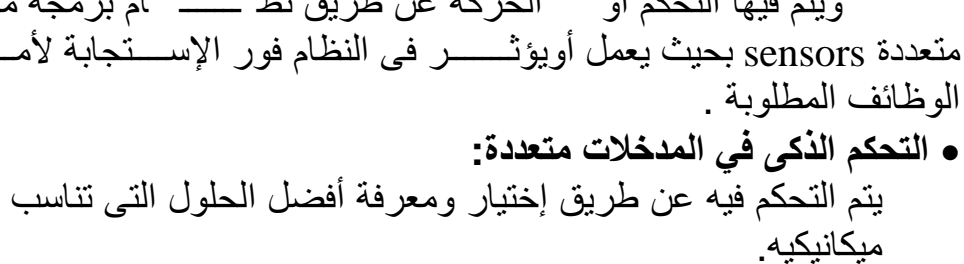

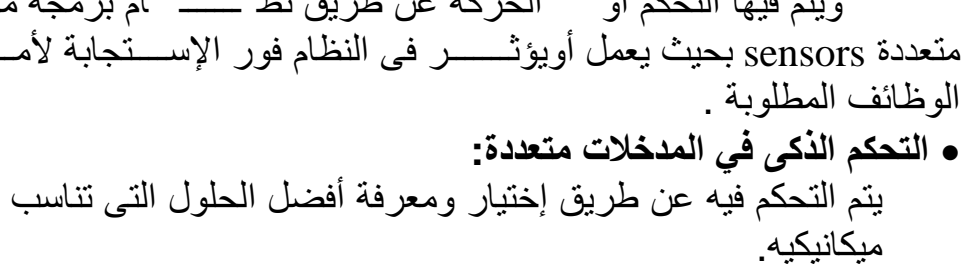

• الأنظمة الخارجية:
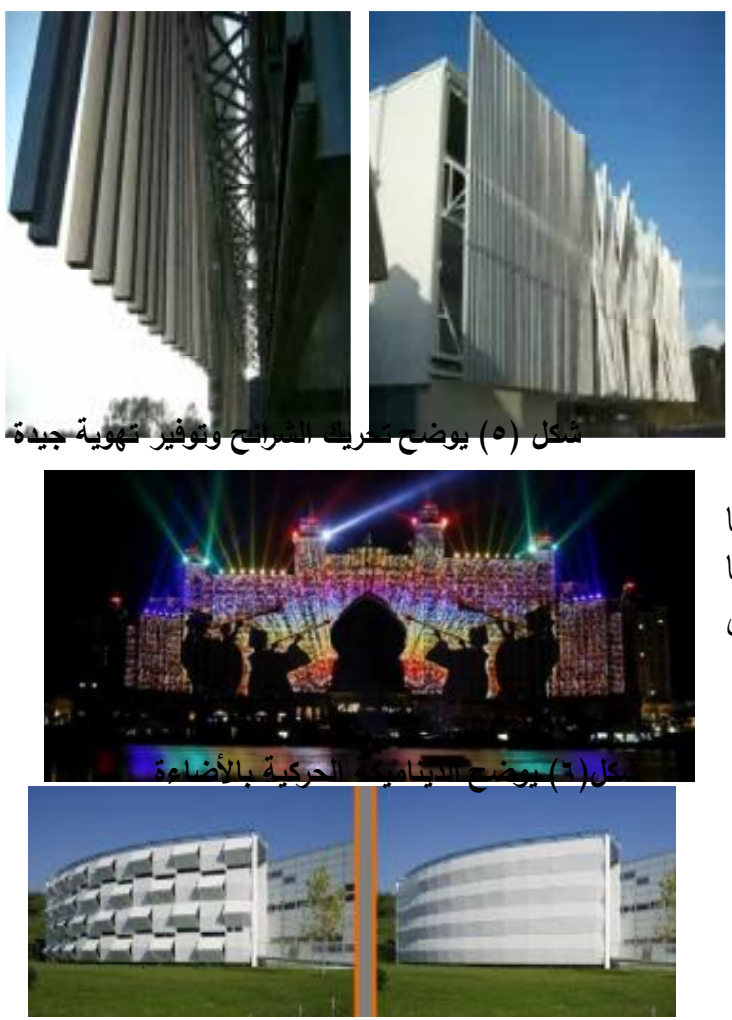

شكل(V) يوضح الديذ
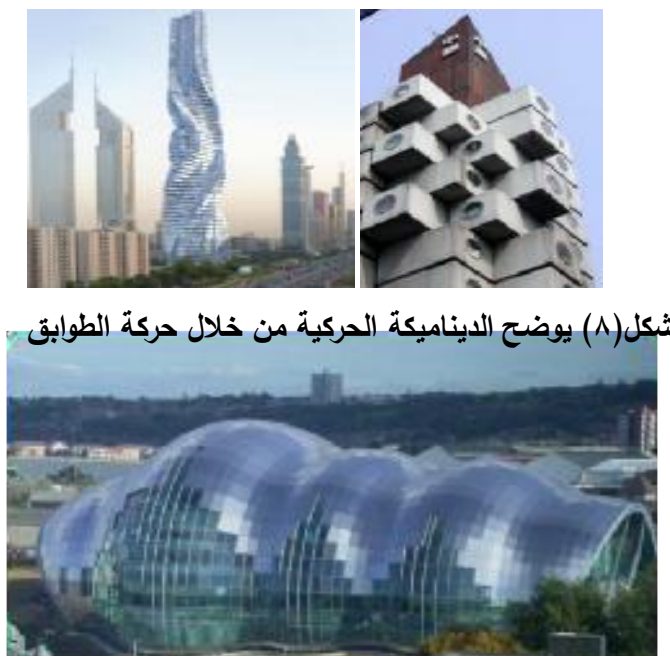

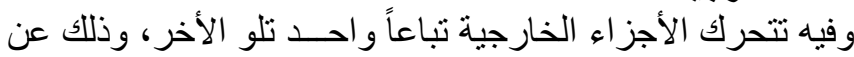

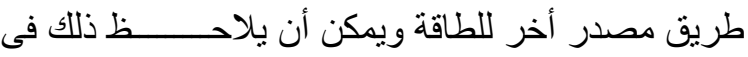

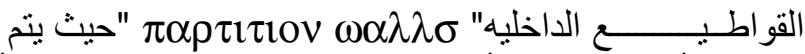

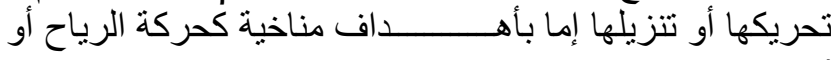

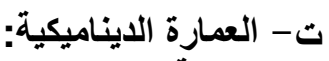

الفكرة الرئيسية للعمارة الايناميكية:

يتم حركة المباني الديناميكية وتشغيلها عن طريقية إنتاجها

لطاقتها الكهربائية بنفسها، وذللك عن طريق النائ استخدام الـ خلابيا

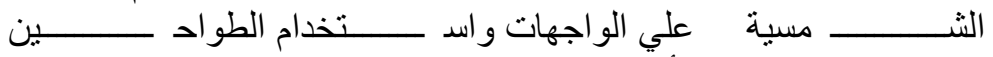

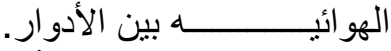

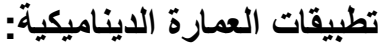

تطبق العمارة الديناميكية من خلال الأنظمة التالية: • الايناميكية الحركية من خلال الحركة بالأضاعة الأنة

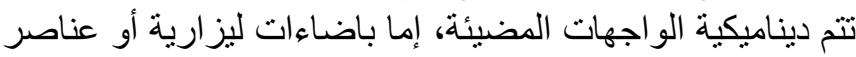

• الديناميكية الحركية من خلال حركة عناصر معمارية: حركة الفتحات بالو اجهة حيث تفتح حركة ونغلق محدثة و اجهات

• الديناميكية الحركية من خلال حركة الطوابق :

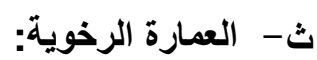

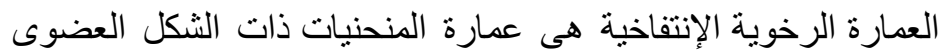

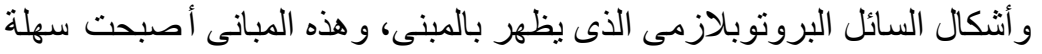




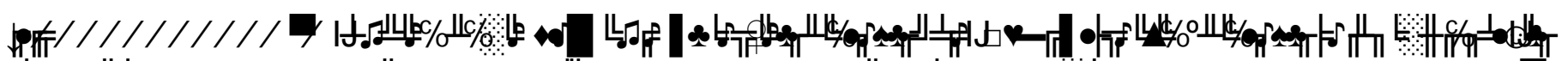

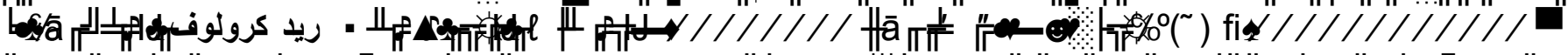

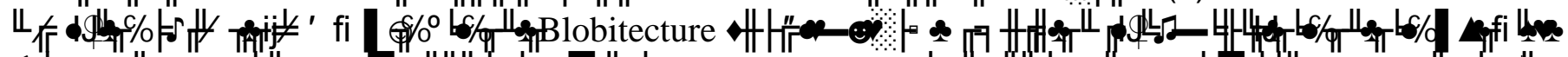

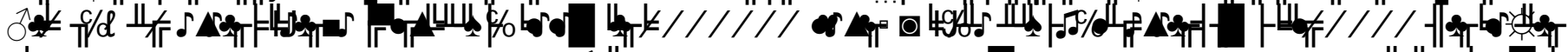

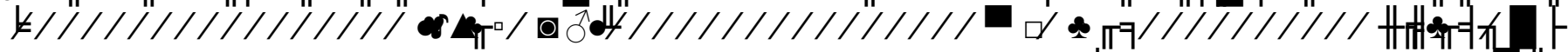
$.1=/ / / / / / / / / / / / / /$ ord on

The Sage Gates head building by شكل (9) يوضح مبنى

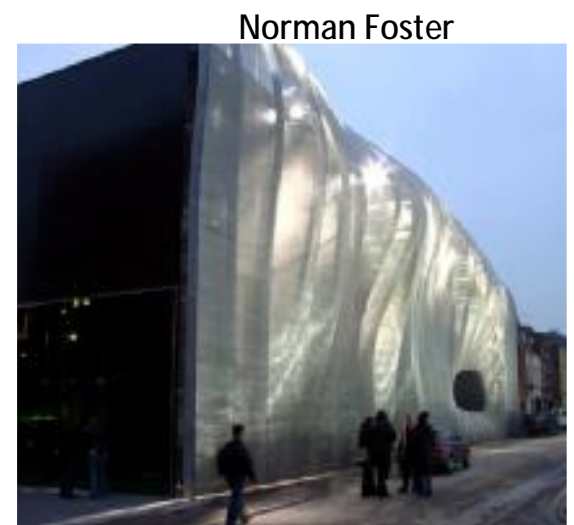

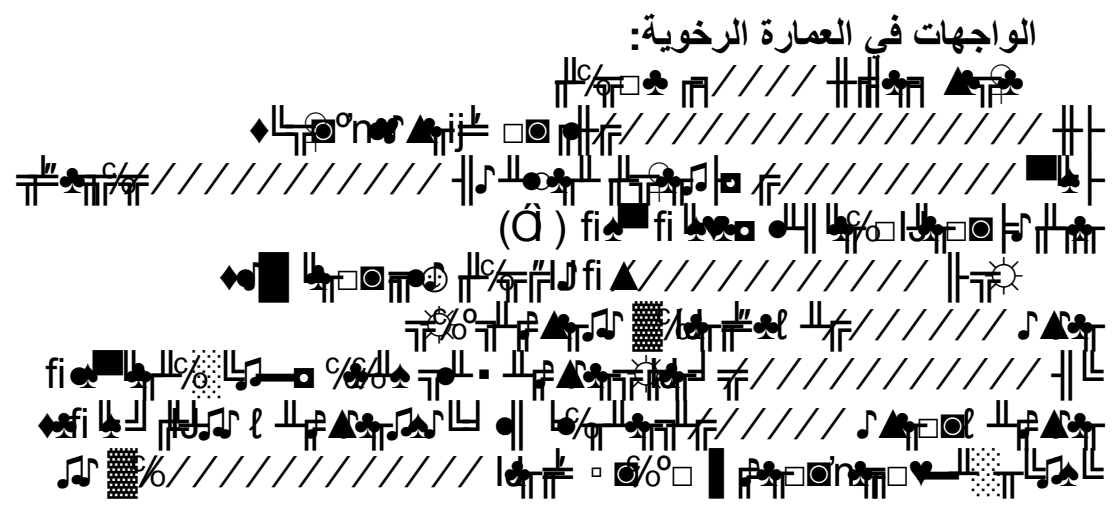

شكل ( • (1) يوضح التثكيل المعماري للواجهات في العمارة الرخوية

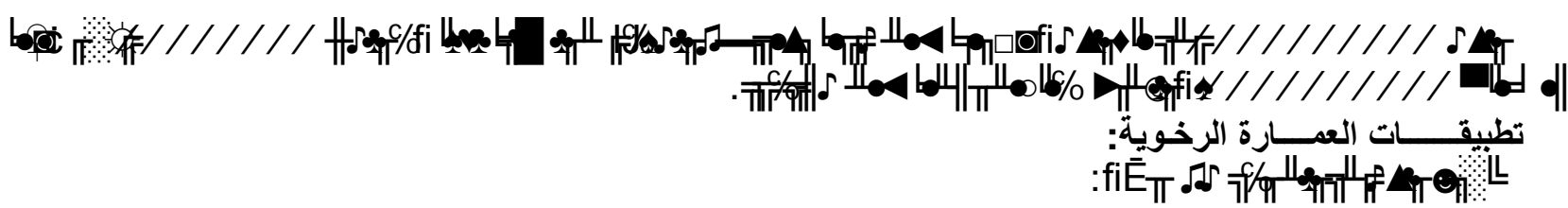

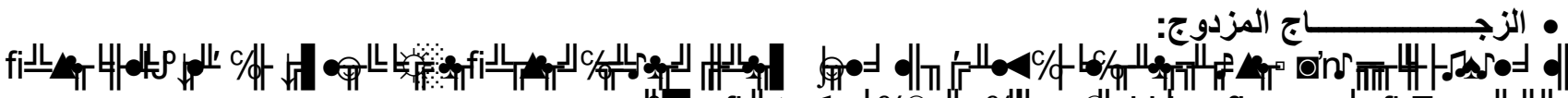

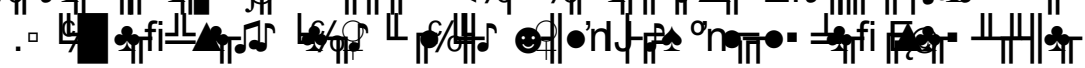

$$
\text { • }
$$

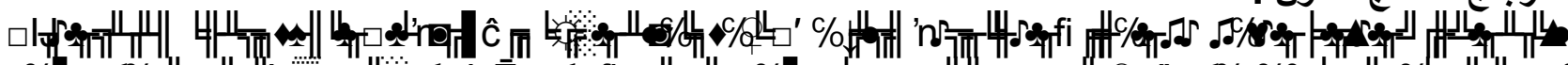

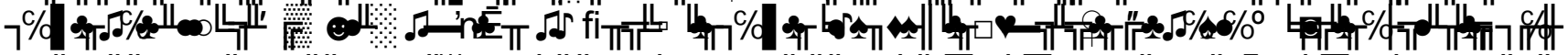

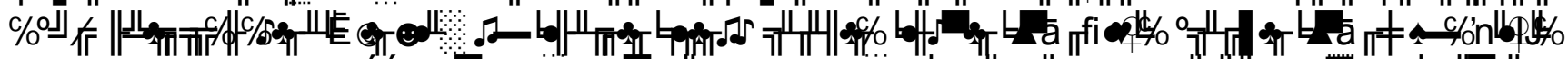

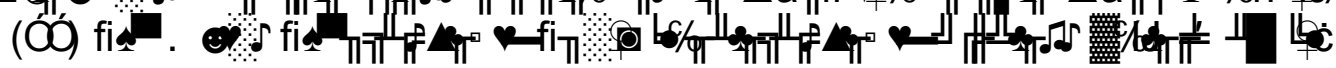
ج- عمارة النانو تكنولوجي:

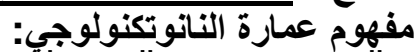

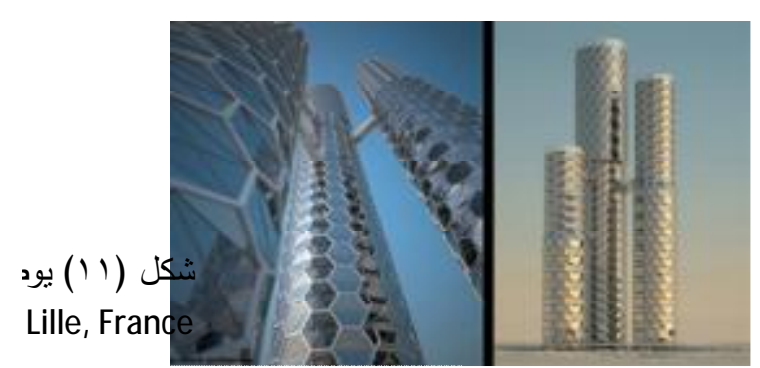

شكل (r ا ) يوضح أبراج عمارة النانو تكنولوجى في دبي

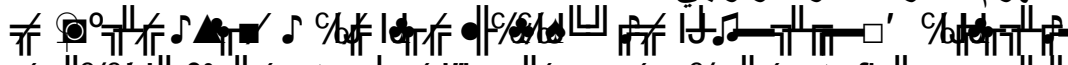

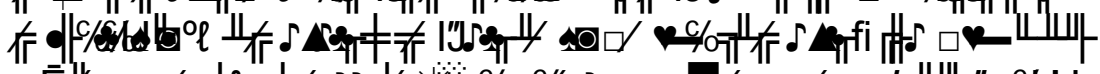

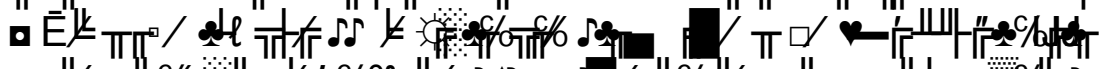

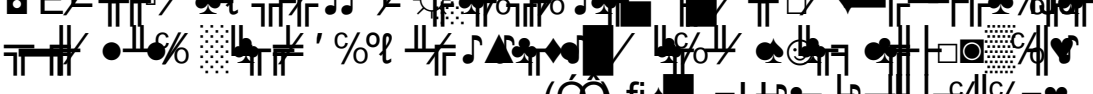
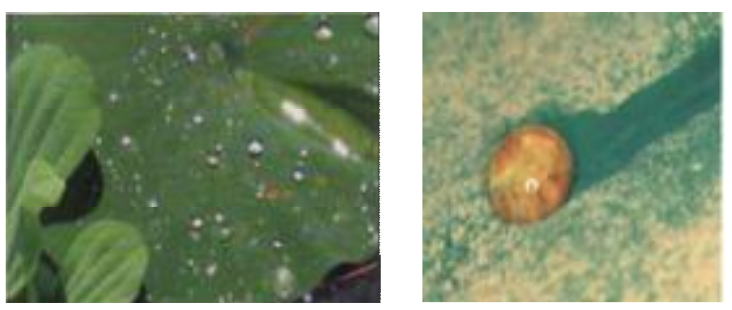

شكل (r I ) يوضح التظيف الأتي من خلال JAUES, 14, تطبيق تقنية تكنولوجيا (وحانتوي (Ó) fi تطبيقات عمارة النانوتكنولوجي:

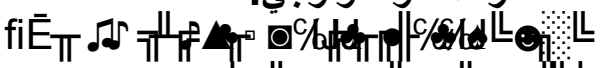

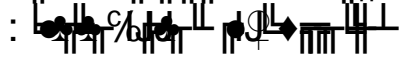

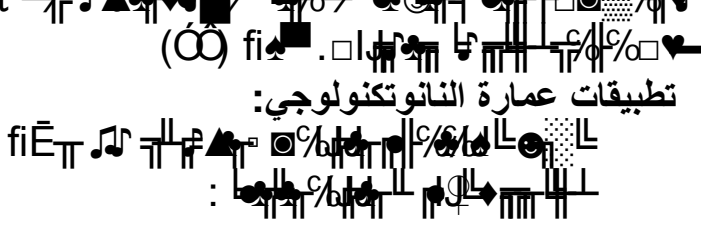

Self-cleaning : التظظف الذاتي

-

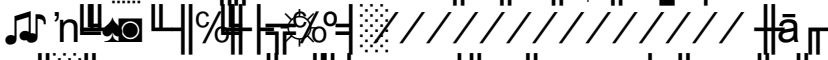
fi 


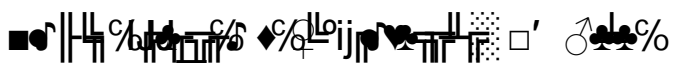

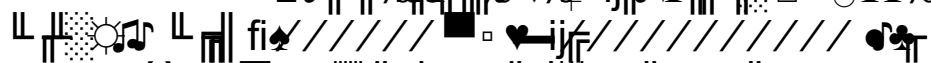

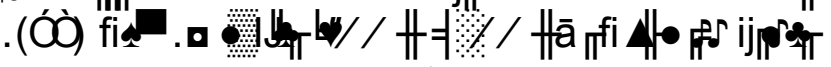

• • التنظيف الذاتي من خلال تقنية التحفيز الضوئي "Photo catalysis"

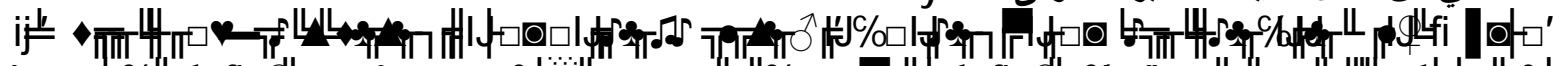

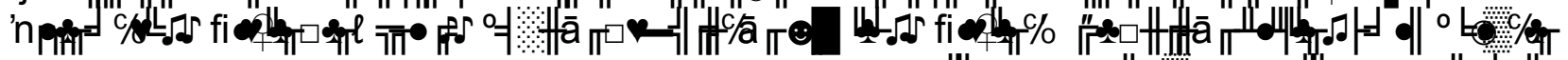

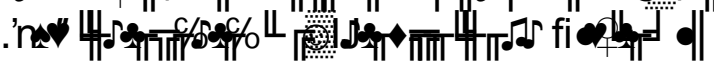

:Easy-to-clean (ETC) التظيف الأتي وذلك من خلال تقنيه

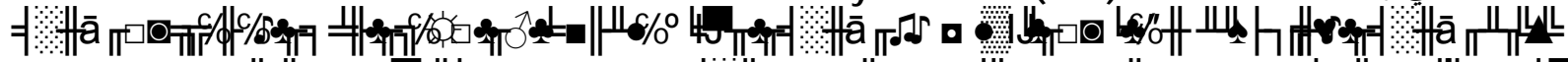
.片梢㕣 •

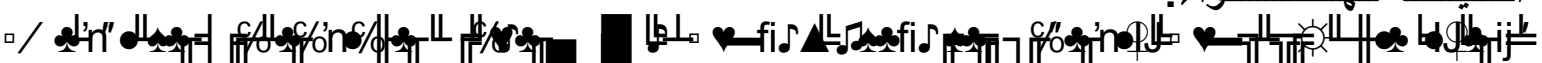

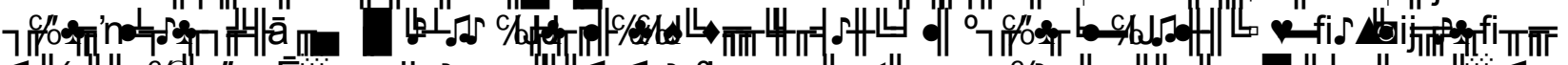

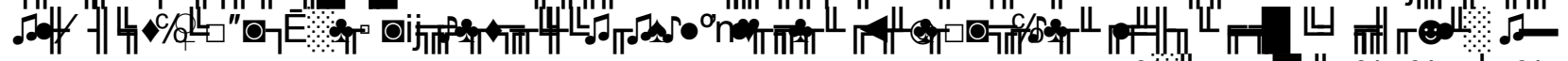

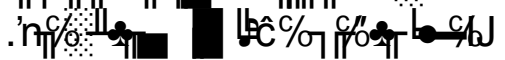

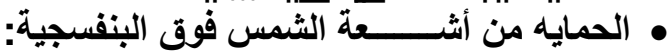
玤

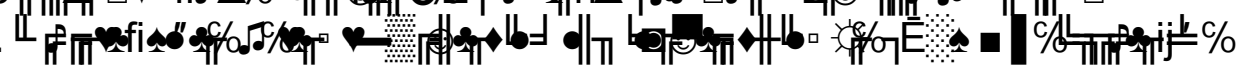
• الألواح الزجاجية التي تتحكم في درجة الاضاءة: TातR

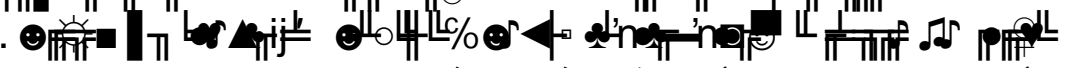
• ألواح العزل الحرارى (ألواح فراغية معزولة):

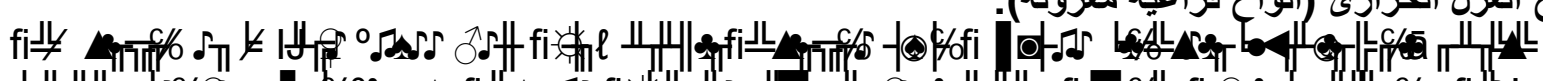
bل

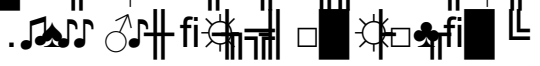

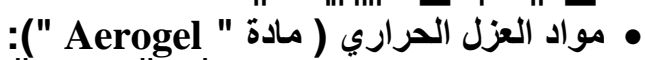

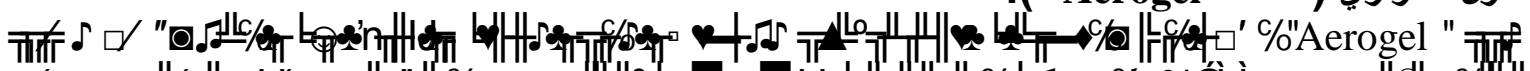

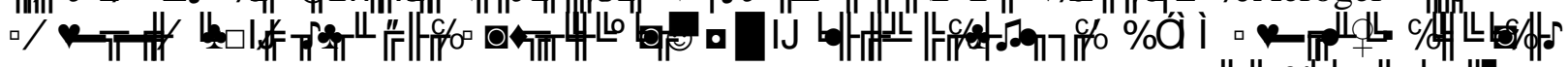
का • • زجاج مضاد للانعكاس بطلاء النانو:

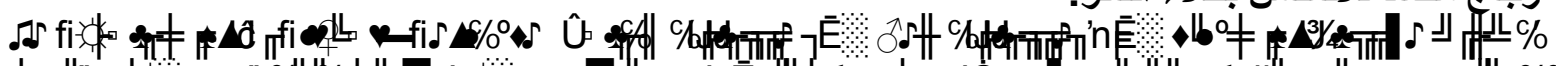

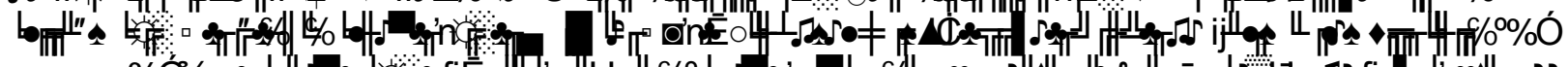

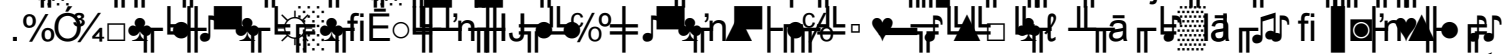

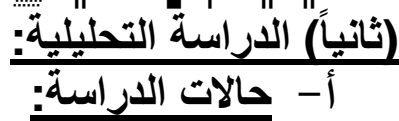

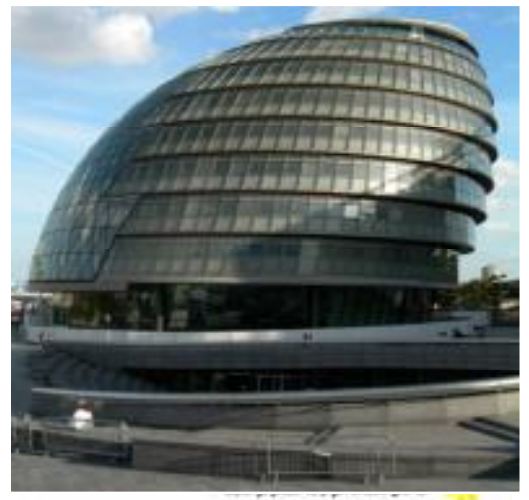

شكل ( أ ) يوضح مبنى بلاية لندن Q

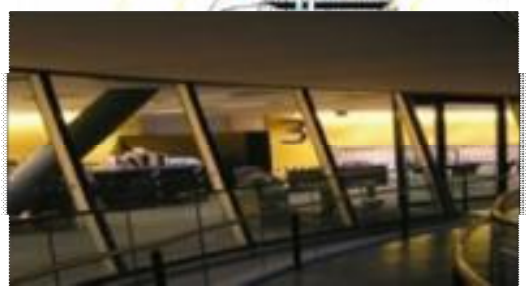

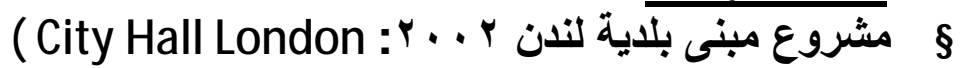

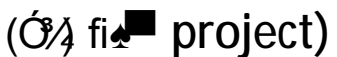

$3 / 4$ 万म 布 $/ 1 / 1 / 1 / 1 /$ क्ل

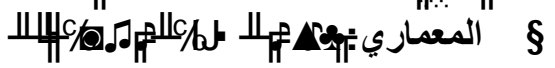
ß

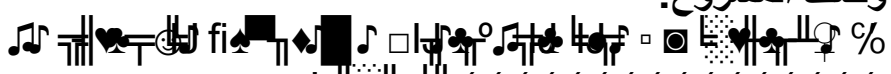

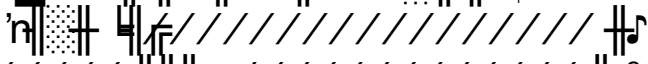

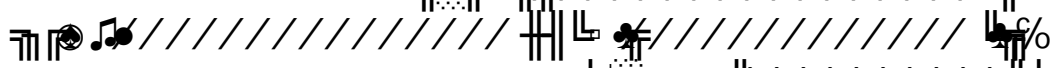

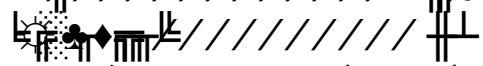

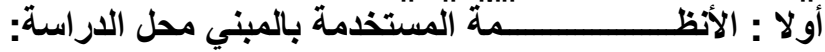

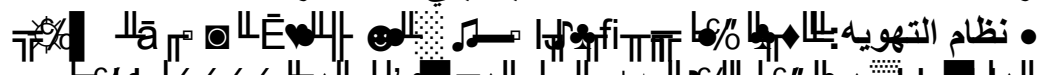

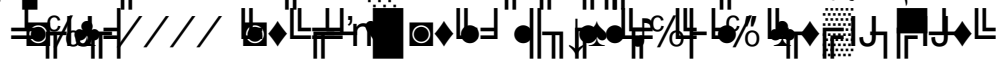




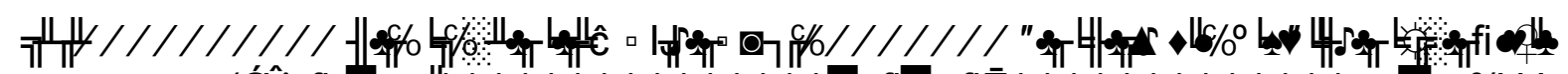
(ố) fia

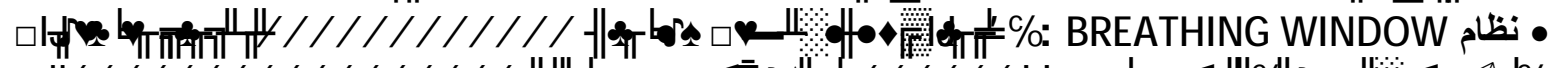

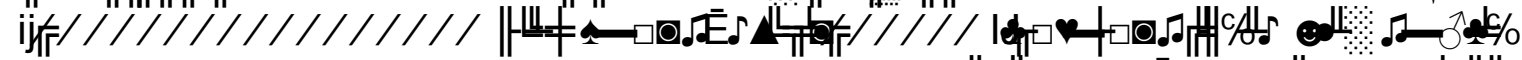

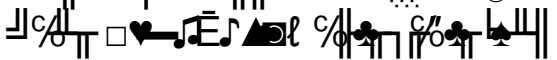

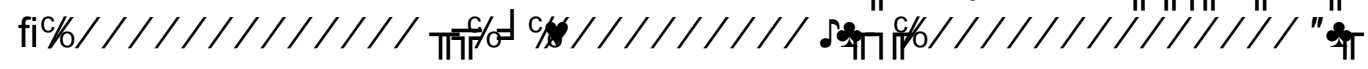
.

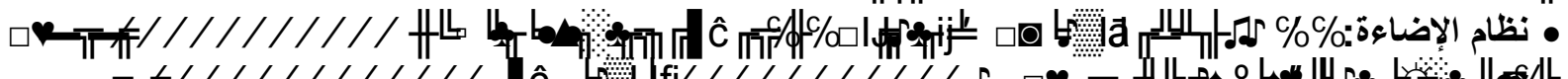

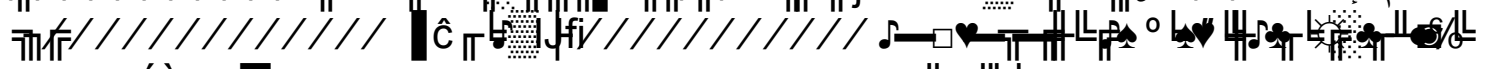
(á) fie. 世

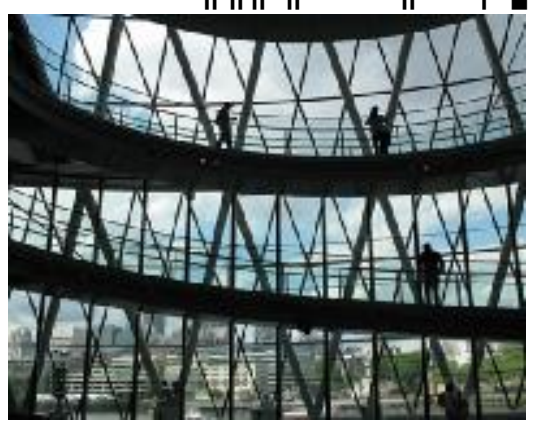

شكل ( 1 ( ) يوضح زجاج النوافذ الموفرة للطاقة فى المبنى

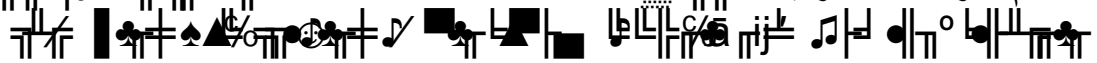

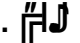

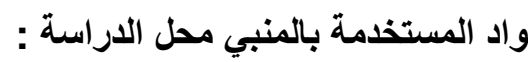

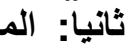

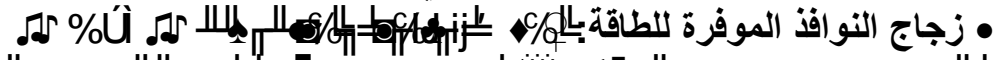
所岸

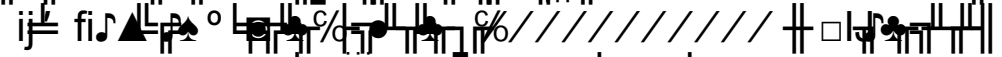

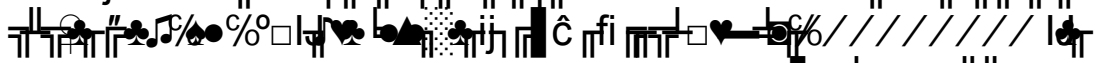

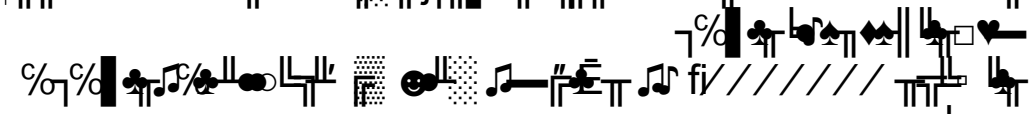

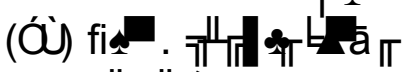

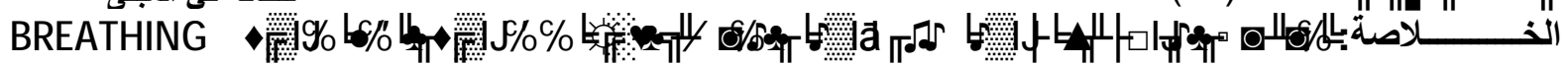

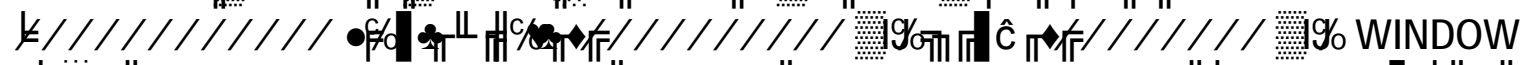

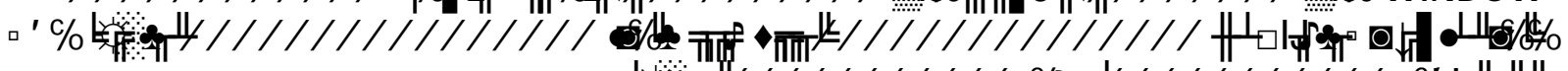

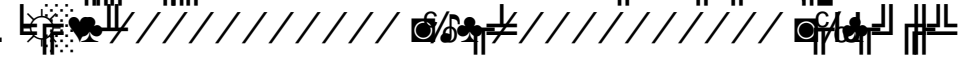

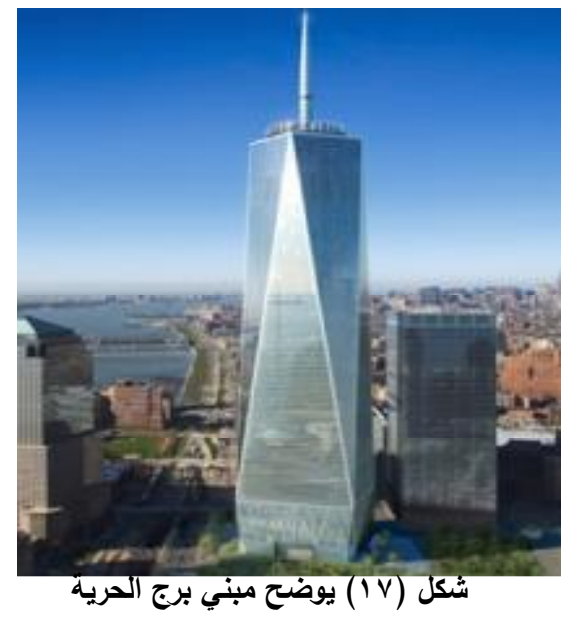

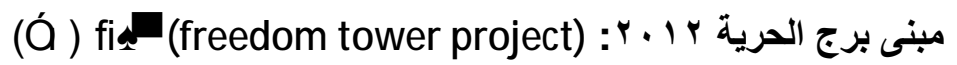

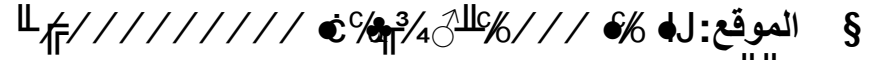

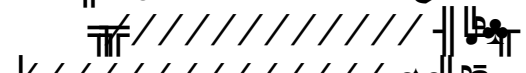
.lk///////////// coldān

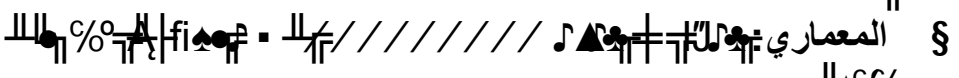
ß وصف المشروع:•

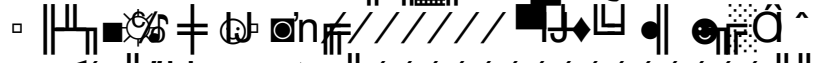

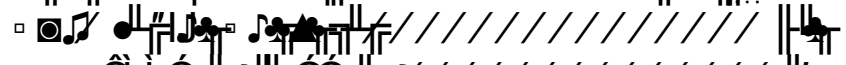

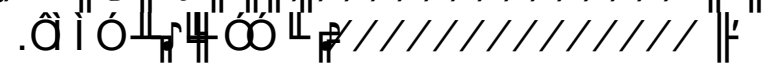

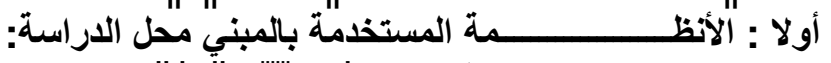

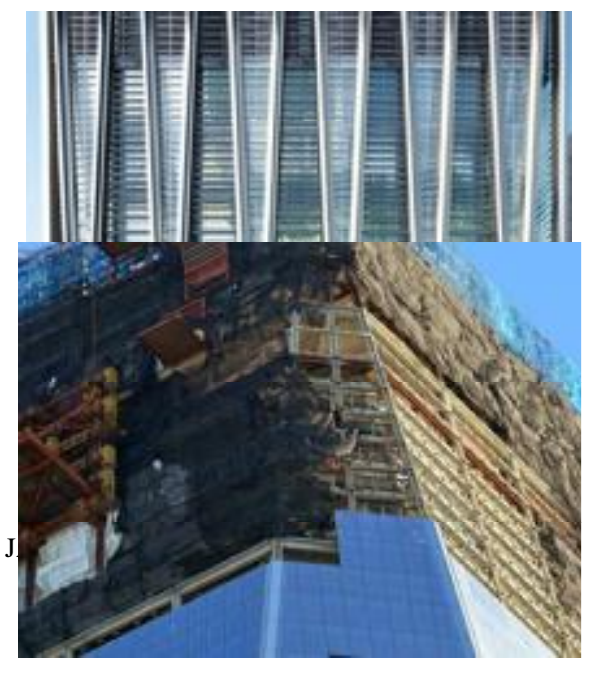

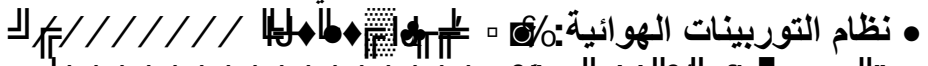

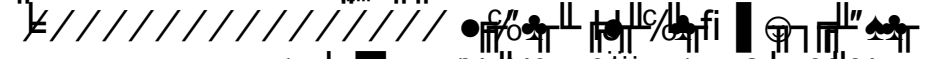

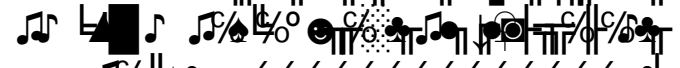

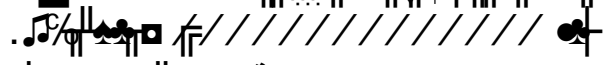
• نظام اللوحات الضوئية:

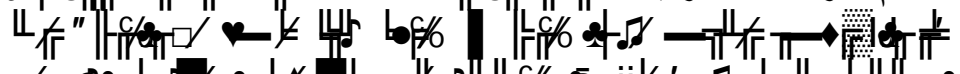

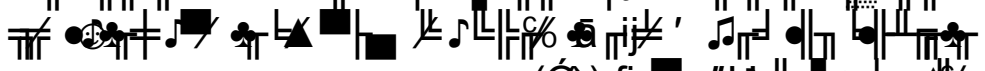

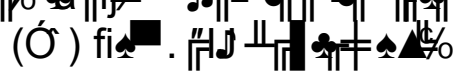




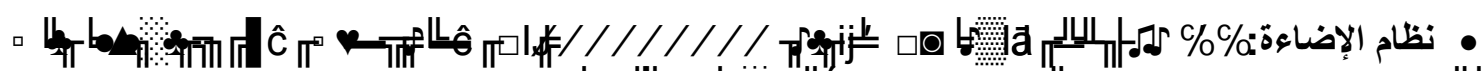

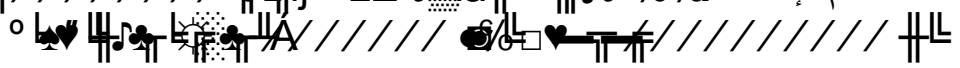

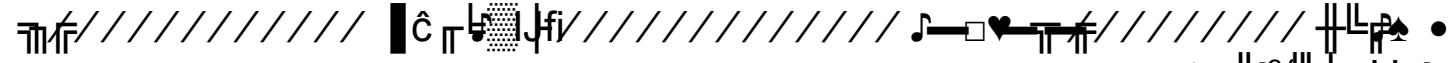

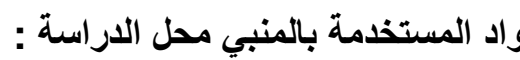

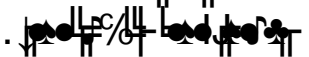

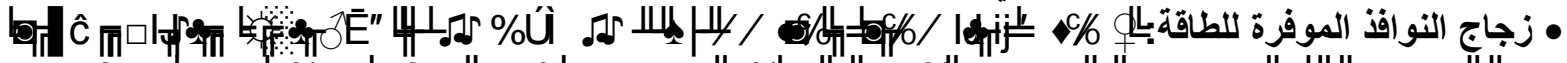

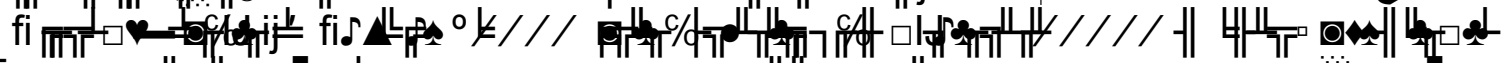

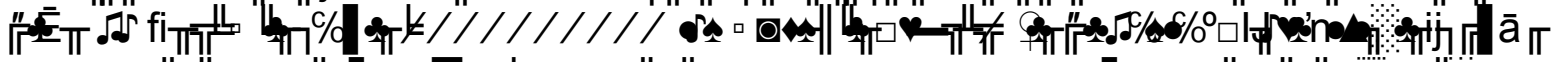

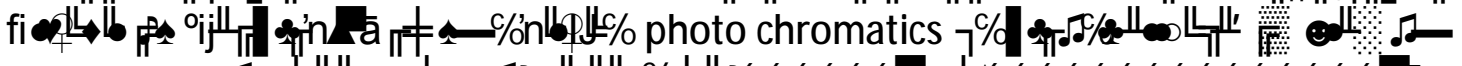

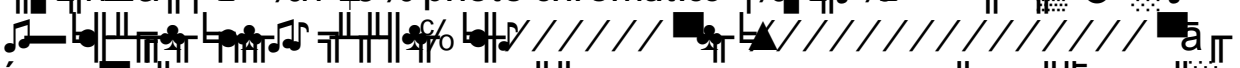

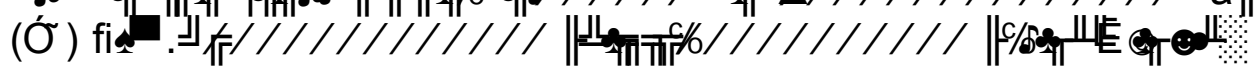

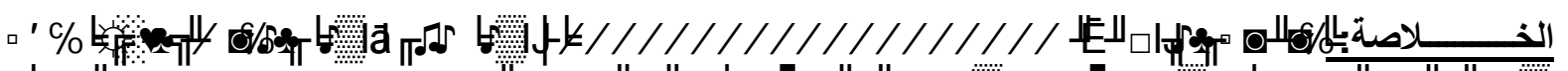

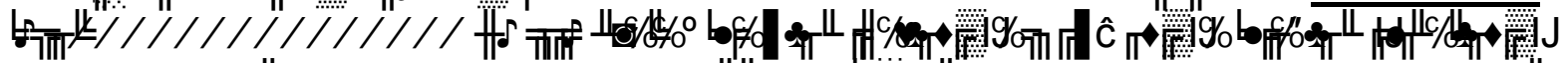

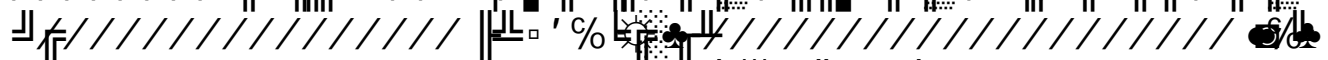
.

(ثالثا) نتائج الاراسة التحليلية للمشروعات السابقة:

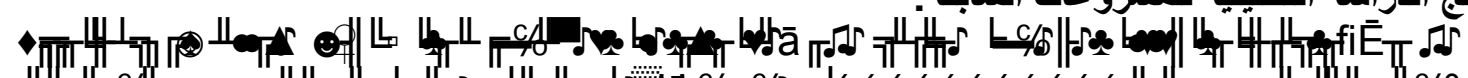

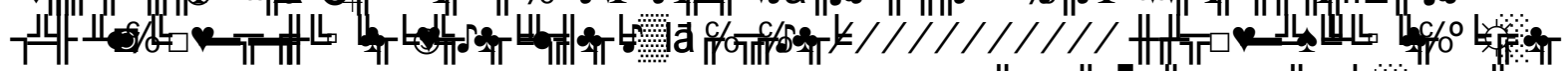

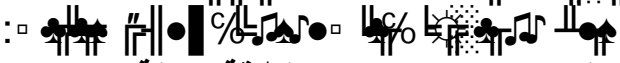

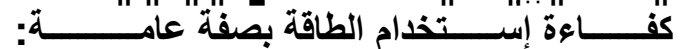

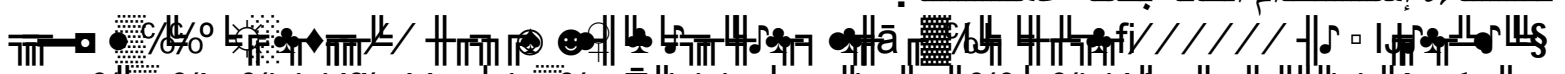

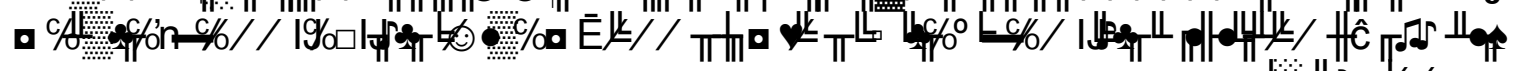

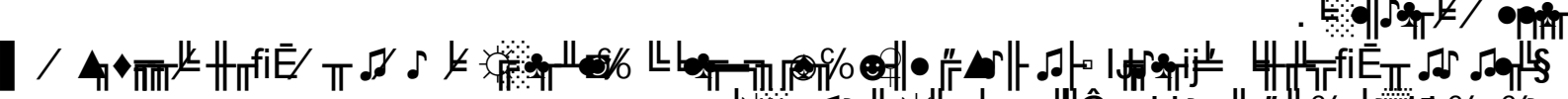
. المواد المختلفة الحديثة المستخدمة في توفير الطاقة:

- L

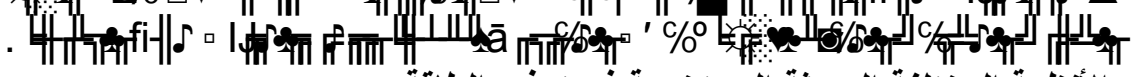
الأنظمة المختلفة الحديثة المستخدمة في توفير الطاقة:

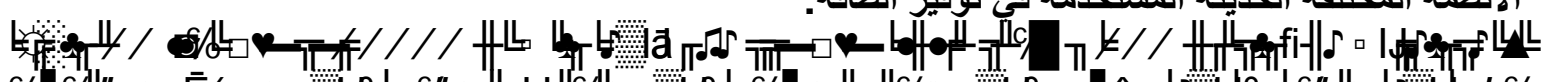

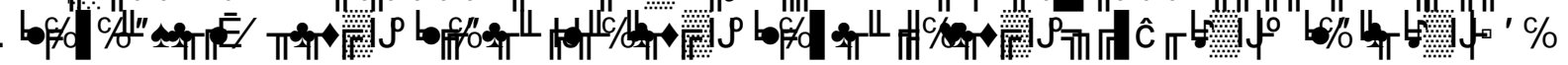
(رابعا) توصيات البحث:

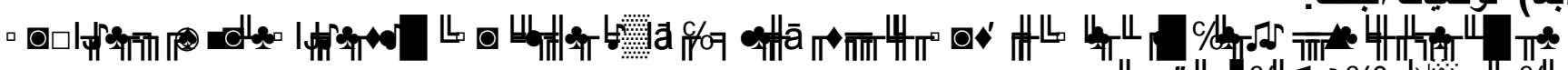

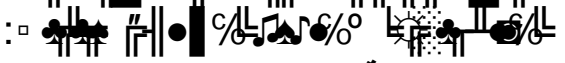
توصيات خاصة بالمهندس المعماري :

- 1, 布

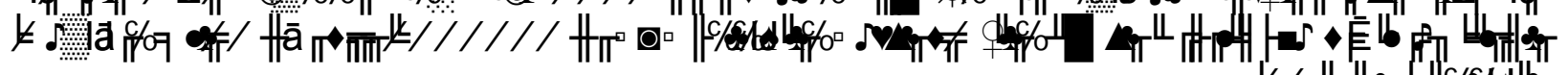

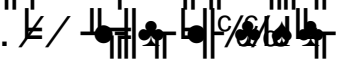

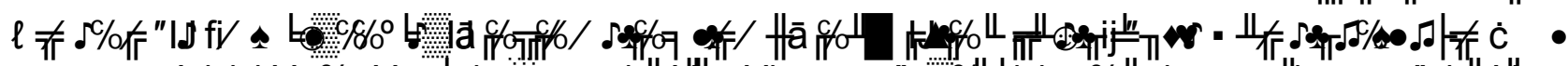

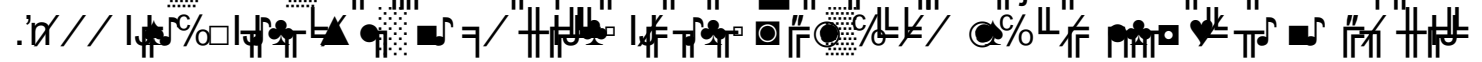

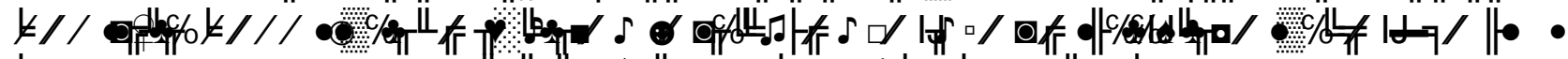

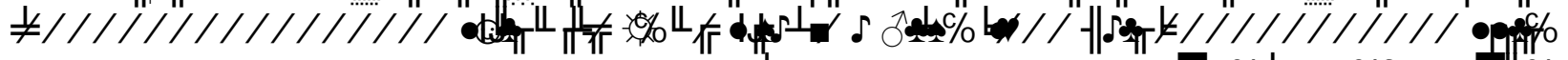
. 4 . 


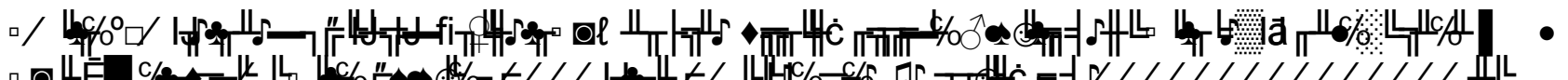

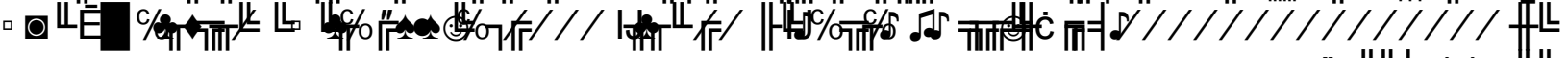
. توصيات خاصة بالهيئات العلمية والبحثية ومتذدي القرار: The $K a$ of

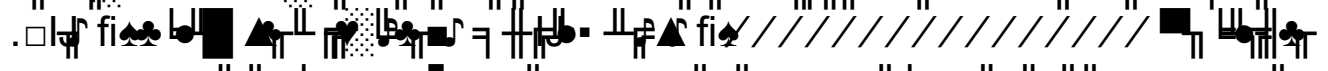

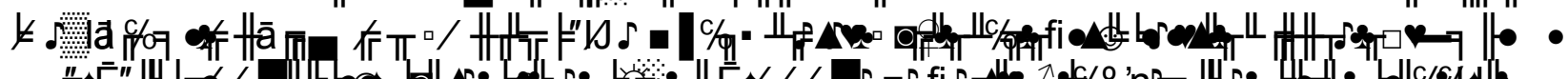
. "T"

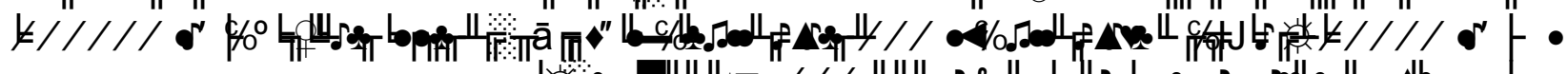
. 
[1] Aurora Cuito (2004): "Designing for High-Tech", The Mit Press, New York, p107, 131, , 145, 156

[Ô John Linden (2001): "Eco-Tech: Sustainable Architecture and High Technology", Butterworth Architecture, Landon, p85.

[Ö Charles J. Kiber (2008) 'Sustainable Construction: Green Building Design and Delivery "New Jersey: John Wiley \& Sons, P45.

[Ú] Charles J. Kiber (2008) 'Sustainable Construction: Green Building Design and Delivery "New Jersey: John Wiley \& Sons, P Ú

[Û] Bungale S. Taranath (2011): "Structural Analysis and Design of Tall Buildings ", Earth Pledge Foundation, New York, p26.

[Ü] [5] http://www.arch-news.net/tag/rene-van-zuuk, Accessed at (20-6-2017).

[ I ] Charles J. Kiber (2008) 'Sustainable Construction: Green Building Design and Delivery "New Jersey: John Wiley \& Sons, P Ú

[^] William Zuk (2007): "Kinetic architecture ", Harry N. Abrams, New York, p18.

[ ] Charles Linn (2011): "Kinetic Architecture Innovative Façades ", Metropolis Books, New York, p97, 107

[đ̊ ] http://www.archello.com/en/project/pearl-river-tower, Accessed at (18-đ̂ -201^).

http://www.greatbuildings.com/architects/Santiago_Calatrava.html, Accessed at (20-Ô -201^).

[O9 ] Mick Eekhout (2008): "Structures and Constructions in Blob Architecture", Butterworth Architecture, Landon, p3.

[Óg Picon Antoine (2010): "Digital Culture in Architecture", Butterworth Architecture, Landon, p43.

[Ọ Jeska Simone (2006): "Von der Burg zum Blob: Kinder entdecken Architektur", Publishers Rotterdam, ISBN, p23.

[Ó] http://alex.academia.edu/profdrmohamedabdelallibrahim/Blog/965/NANOARCHITECTURE

[ô] Leydecker, Sylvia (2008): "Nano Materials", Patrick. Springer, Landon, p43, 70

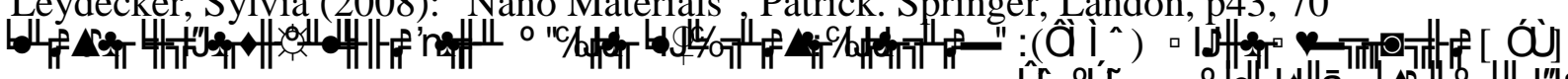

Ó ] Ratner, Daniel (2002): " Nanotechnology: A Gentle Introduction to the Next Big Idea" Patrick. Springer, Landon, p65.

[Ớ ] Pradeep, T.McGrew Hill (2007): " Nano the Essentials: Understanding Nano science and Technology", New

[Ớ ] Mark P. Sarkisian (2011): " Designing Tall Buildings: Structure as Architecture", John Wiley \& Sons, Landon, p53-54.

[Q̂̉ ] Charles River Editors (2016):"The Freedom Tower: The History of New York City's One World Trade

Center", Publisher: Create Space Independent Publishing Platform, ISBN-10 